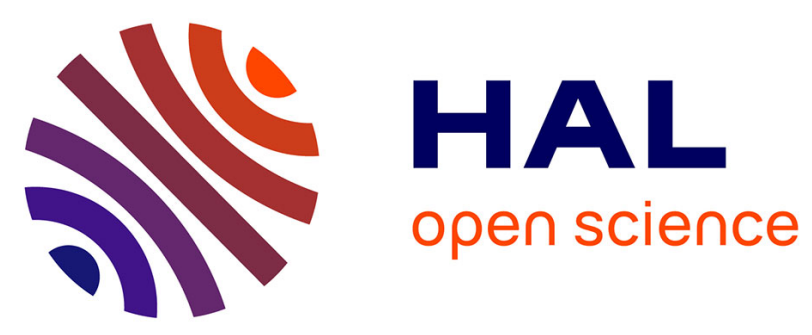

\title{
Roflumilast attenuates pulmonary inflammation upon segmental endotoxin challenge in healthy subjects: A randomized placebo-controlled trial
}

Jens M. Hohlfeld, Kerstin Schoenfeld, Mehyar Lavae-Mokhtari, Frank Schaumann, Meike Mueller, Dirk Bredenbroeker, Norbert Krug, Robert

Hermann

\section{To cite this version:}

Jens M. Hohlfeld, Kerstin Schoenfeld, Mehyar Lavae-Mokhtari, Frank Schaumann, Meike Mueller, et al. Roflumilast attenuates pulmonary inflammation upon segmental endotoxin challenge in healthy subjects: A randomized placebo-controlled trial. Pulmonary Pharmacology \& Therapeutics, 2008, 21 (4), pp.616. 10.1016/j.pupt.2008.02.002 . hal-00499153

\section{HAL Id: hal-00499153 https://hal.science/hal-00499153}

Submitted on 9 Jul 2010

HAL is a multi-disciplinary open access archive for the deposit and dissemination of scientific research documents, whether they are published or not. The documents may come from teaching and research institutions in France or abroad, or from public or private research centers.
L'archive ouverte pluridisciplinaire HAL, est destinée au dépôt et à la diffusion de documents scientifiques de niveau recherche, publiés ou non, émanant des établissements d'enseignement et de recherche français ou étrangers, des laboratoires publics ou privés. 


\section{Author's Accepted Manuscript}

Roflumilast attenuates pulmonary inflammation upon segmental endotoxin challenge in healthy subjects: A randomized placebo-controlled trial

Jens M. Hohlfeld, Kerstin Schoenfeld, Mehyar LavaeMokhtari, Frank Schaumann, Meike Mueller, Dirk Bredenbroeker, Norbert Krug, Robert Hermann

PII: S1094-5539(08)00017-5

DOI: $\quad$ doi:10.1016/j.pupt.2008.02.002

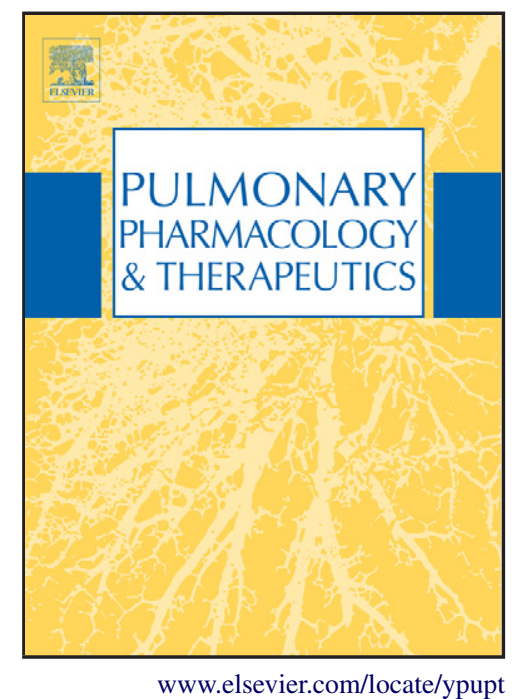

Reference: $\quad$ YPUPT 828

To appear in: Pulmonary Pharmacology \& Therapeutics

Received date: 2 November 2007

Revised date: 10 February 2008

Accepted date: 13 February 2008

Cite this article as: Jens M. Hohlfeld, Kerstin Schoenfeld, Mehyar Lavae-Mokhtari, Frank Schaumann, Meike Mueller, Dirk Bredenbroeker, Norbert Krug and Robert Hermann, Roflumilast attenuates pulmonary inflammation upon segmental endotoxin challenge in healthy subjects: A randomized placebo-controlled trial, Pulmonary Pharmacology \& Therapeutics (2008), doi:10.1016/j.pupt.2008.02.002

This is a PDF file of an unedited manuscript that has been accepted for publication. As a service to our customers we are providing this early version of the manuscript. The manuscript will undergo copyediting, typesetting, and review of the resulting galley proof before it is published in its final citable form. Please note that during the production process errors may be discovered which could affect the content, and all legal disclaimers that apply to the journal pertain. 
Full length article

\section{Roflumilast attenuates pulmonary inflammation upon segmental endotoxin challenge in} healthy subjects: A randomized placebo-controlled trial

Jens M. Hohlfeld ${ }^{1 *}$, Kerstin Schoenfeld ${ }^{2}$, Mehyar Lavae-Mokhtari ${ }^{1}$, Frank Schaumann ${ }^{1}$, Meike Mueller ${ }^{1}$, Dirk Bredenbroeker ${ }^{2}$, Norbert $\operatorname{Krug}^{1}$, Robert Hermann ${ }^{2}$

${ }^{1}$ Fraunhofer Institute of Toxicology and Experimental Medicine, Hannover, Germany

${ }^{2}$ Nycomed GmbH, Konstanz, Germany (formerly ALTANA Pharma AG, Konstanz)

*Corresponding author and reprint requests:

Jens M. Hohlfeld, MD

Department of Clinical Airway Research

Fraunhofer Institute Toxicology and Experimental Medicine (ITEM)

Nikolai-Fuchs-Str. 1A, D-30625 Hannover, Germany

Tel. +49-511-5350-604, Fax: +49-511-5350-620

hohlfeld@item.fraunhofer.de

Word count: 3620 words (Introduction, Methods, Results, Discussion)

24 pages, 3 tables, 3 figures 


\section{Abstract}

Rationale: Roflumilast, an investigational, targeted phosphodiesterase 4 inhibitor, reduces the in vitro and in vivo inflammatory activity of cells such as neutrophils, eosinophils, macrophages, and monocytes.

Objectives: The aim of this study was to explore the anti-inflammatory properties of roflumilast in a human model of segmental bronchial endotoxin challenge.

Methods: In a randomized, placebo-controlled, double-blind, single-center parallelgroup study, 37 healthy subjects of either sex were treated for 28 days with either oral roflumilast $500 \mu \mathrm{g}$ once daily or placebo. At Day 29, a baseline bronchoalveolar lavage was performed, followed by segmental endotoxin challenge $(4 \mathrm{ng} / \mathrm{kg}$ ) and saline control challenge. After $24 \mathrm{~h}$, bronchoalveolar lavage fluid was sampled from the challenged segments and cells were counted and differentiated.

Results: After endotoxin challenge, influx of total cells (difference from baseline) in bronchoalveolar lavage of roflumilast treated subjects was $36 \%$ lower than with placebo $(\mathrm{p}=0.02)$. Correspondingly, the influx of neutrophils and eosinophils of roflumilast treated subjects was $39 \%(\mathrm{p}=0.02)$ and $74 \%(\mathrm{p}=0.01)$ lower than with placebo, respectively. In contrast, endotoxin-induced influx of monocytes was not different between roflumilast and placebo treated subjects. No significant differences existed between the groups pertaining to endotoxin-induced influx of macrophages and lymphocytes. Roflumilast was well tolerated. No unexpected or serious treatment-emergent signs and symptoms were observed.

Conclusions: Roflumilast attenuated the endotoxin-induced influx of neutrophils and eosinophils into the airways. This study demonstrates the anti-inflammatory properties of roflumilast on bronchoalveolar granulocytes in endotoxin-induced airway inflammation in healthy subjects. (Word count: 240 words)

Keywords: randomized controlled trial; bronchoscopy; bronchoalveolar lavage; phosphodiesterase inhibitors; experimental lung inflammation 


\section{INTRODUCTION}

Chronic obstructive pulmonary disease (COPD) is a leading cause of chronic morbidity and death world-wide with a predicted further increase of prevalence and mortality in the coming decades [1]. The disease is characterized by airflow limitation that is not fully reversible, progressive, and associated with an abnormal inflammatory airway response to inhaled noxa, mainly cigarette smoke [2]. The cellular inflammatory response in the airways is predominated by neutrophils [3], monocytes, and macrophages as well as CD8+ Tlymphocytes. These inflammatory cells produce a variety of cytokines and chemokines, which stimulate the inflammatory processes and attract further inflammatory cells to the site of inflammation. Apart from the aforementioned cells, eosinophils may also play a role in course of acute exacerbations of COPD [4].

Endotoxin, a cell wall component of gram-negative bacteria, is ubiquitously present as contaminant on airborne particles including cigarette smoke [5]. Upon inhalation, endotoxin challenges the innate immune system thereby inducing a robust inflammatory response in human airways, which is predominated by neutrophils [6]. After segmental bronchial instillation of endotoxin, elevations of neutrophils, monocytes, macrophages, and lymphocytes as well as pro-inflammatory mediators such as interleukin (IL)-8 and tumor necrosis factor alpha (TNF- $\alpha$ ) occur in the bronchoalveolar lavage (BAL) fluid [7]. Endotoxin could thus initiate and sustain the inflammation in smoking COPD patients and might be involved in the pathophysiology of gram-negative bacterial exacerbations of the disease.

Given the similarities between the endotoxin-induced inflammatory response in the lung and the airway inflammation seen in COPD patients, endotoxin challenge could be a valuable pharmacodynamic model for the characterization of the anti-inflammatory properties of novel investigational drugs developed for the treatment of COPD. Hitherto, the model of endotoxin-induced airway inflammation in humans has been used to determine the antiinflammatory drug effect of salmeterol, prednisolone and the PDE4 inhibitor cilomilast $[8,9]$. 
While prednisolone and cilomilast failed to reduce airway inflammation in induced sputum, salmeterol reduced cell recruitment in bronchoalveolar lavage following endotoxin inhalation. However, a proof for salmeterol or $\beta$-agonists as antiinflammatory drugs in patients with COPD is missing.

Roflumilast is a targeted oral, once-daily phosphodiesterase 4 (PDE4) inhibitor under investigation for the treatment of COPD [10]. Inhibition of PDE4 increases intracellular cyclic adenosine monophosphate (cAMP) concentrations, which in turn leads to activation of protein kinase A. Subsequent phosphorylation and inactivation of target transcription factors ultimately results in attenuation of cellular inflammatory activity [11, 12]. Accordingly, roflumilast inhibits the release of inflammatory cytokines and chemokines in human cells in vitro and in animal models of COPD and asthma in vivo [13-16]. In these animal models, roflumilast also reduces the pulmonary accumulation of neutrophils, eosinophils, monocytes, and macrophages after endotoxin or allergen challenge. In recent clinical studies, roflumilast was shown to reduce eosinophils in induced sputum of patients with asthma [17] and to reduce the number of neutrophils and eosinophils in induced sputum of patients with COPD, which was paralleled by an improvement of post-bronchodilator $\mathrm{FEV}_{1}$ [18]. Furthermore, large clinical studies in COPD indicate that roflumilast $500 \mu \mathrm{g}$ once daily results in significant improvements in lung function and may potentially reduce the rate of the exacerbation in patients with COPD [19].

The aim of this randomized, placebo-controlled, double-blind, single-center study in healthy subjects was to investigate the effects of roflumilast on the recruitment of inflammatory cells into the airways and associated inflammatory markers following segmental bronchial endotoxin challenge. (553 words) 


\section{METHODS}

\section{Subjects}

Forty-eight healthy subjects of either sex aged 18 to 45 years with normal body weight according to body mass index between 18 and $28 \mathrm{~kg} / \mathrm{m}^{2}$ and normal pulmonary function $\left(\mathrm{FEV}_{1} \geq 80 \%\right.$ of predicted) were included in the study. All subjects were non-smokers, they had negative skin prick tests and none had respiratory tract infection four weeks prior to inclusion. Except for concomitant medications required for bronchoscopy, paracetamol for treatment of headache or other painful conditions, and hormonal contraceptives in female subjects with childbearing potential, no other concomitant medications were allowed throughout the study.

The protocol was approved by the Ethics Committee of the Hannover Medical School, Germany. The study was conducted in accordance with the Declaration of Helsinki (Somerset West Amendment, 1996) and the ICH Guideline on Good Clinical Practice (Note for Guidance on Good Clinical Practice (CPMP/ICH/135/95), Jan. 17, 1997) and performed at the Clinical Research Unit of the Fraunhofer Institute for Toxicology and Experimental Medicine, Hannover, Germany. Written informed consent was obtained from each subject before any study-related procedures started.

\section{Study Design}

This study was conducted according to a randomized, double-blind, placebocontrolled, parallel-group, single-center, 4-week design (Figure 1). Forty-three subjects were randomized to receive oral roflumilast $500 \mu \mathrm{g}$ once daily or placebo for $28 \pm 3$ days. Study medication was taken at home and subjects were seen weekly to check treatment compliance by drug accountability and blood sampling for retrospective assessment of roflumilast and its primary active metabolite roflumilast $\mathrm{N}$-oxide. On the last day of treatment, subjects underwent bronchoscopy with BAL and segmental instillation of endotoxin and saline. 
Twenty-four hours later, subjects underwent a second bronchoscopy for the collection of BAL fluid from the challenged segments. The 24-h interval between endotoxin challenge and postchallenge BAL was chosen because the change of inflammatory cell counts from baseline was the main study objective and cellular changes in BAL fluid after endotoxin challenge were reported to be maximal at this time point [7]. BAL fluid from both days was processed and analyzed for inflammatory cells and mediators as described below.

\section{Bronchoscopic Procedure}

Bronchoscopies were performed according to the Fraunhofer Institute study site standard operating procedure, which is based on guidelines for investigative bronchoscopies [20]. Details of the principal bronchoscopic procedure with BAL and segmental bronchial instillation have been described previously $[21,22]$. Briefly, BAL was performed with $6 \mathrm{x}$ $20 \mathrm{ml}$ warmed saline $(0.9 \%)$ whereof the first recovered aliquot was discarded. On the last day of treatment with roflumilast, baseline BAL was done in the anterior segment of the left lower lobe. Clinical Center Reference Endotoxin (National Institute of Health - Warren Grant Magnuson Clinical Center, Bethesda, MD, USA) at a dose of $4 \mathrm{ng} / \mathrm{kg}$ body weight was diluted in $10 \mathrm{ml}$ of saline $(0.9 \%)$ and instilled to the medial segment of the middle lobe using a sterile catheter introduced through the working channel of the bronchoscope. As a control challenge, $10 \mathrm{ml}$ of saline $(0.9 \%)$ were applied to the medial segment of the lingula using a new catheter for instillation. BAL was obtained $24 \mathrm{~h}$ later from both challenged segments.

\section{Assessment of Anti-inflammatory Pharmacodynamic Effects}

Total cells, neutrophils, eosinophils, monocytes, macrophages, and lymphocytes in BAL were counted and differentiated using light microscopy [21]. Because monocytes could not be differentiated from macrophages by light microscopy, monocytes were counted by flow cytometry using granularity and expression of CD14 for identification as described 
before [22]. Cell-free BAL supernatants were stored frozen in aliquots at $-70^{\circ} \mathrm{C}$ until further analysis.

BAL supernatants were analyzed for TNF- $\alpha$, IL-6, IL-8, matrixmetalloproteinase (MMP)-9 and monocyte chemoattractant protein (MCP)-1 using commercially available ELISA (enzyme-linked immunosorbent assays) kits (all obtained from R\&D Systems GmbH, Wiesbaden, Germany except, MMP-9 from Amersham Biosciences, Freiburg, Germany). Nitrate and nitrite were determined by using the Sievers Nitric Oxide Analyzer (NOA 280i ${ }^{\circledR}$, General Electric Analytical Instruments, Urmston, UK), which is a high-sensitivity detector for measuring nitric oxide based on a gasphase chemiluminescent reaction [23].

\section{Assessment of Safety}

Physical examinations and electrocardiogramms (ECG) were conducted at the screening visit and at a final visit. Clinical laboratory parameters were also assessed at screening and end-of-study examination and they were additionally monitored weekly during the treatment phase. Vital signs (blood pressure, pulse rate) were measured at screening, before randomization, before bronchoscopy, and at a final visit. At each visit, subjects were asked whether or not they had experienced any adverse event (AE). Any use of concomitant medication was recorded.

Lung function was measured according to standard procedures [24] by spirometry (Masterscope, Viasys Healthcare, Höchberg, Germany) at screening, prior to bronchoscopy, and at study termination. Following bronchoscopy with segmental endotoxin instillation, monitoring of lung function was additionally performed every $2 \mathrm{~h}$ with a hand-held spirometer (Asthma Monitor AM1, Viasys Healthcare, Höchberg, Germany) until bedtime. 


\section{Sample Size and Statistics}

The main interest of our study was to explore cellular changes and to assess potential effects of roflumilast on the influx of neutrophils, eosinophils, monocytes, macrophages and lymphocytes after endotoxin challenge.

Assuming a normal distribution of the aforementioned cell variables, a sample size of 34 subjects (total of both treatment groups) is considered sufficient to ensure a power of at least $80 \%$ in correctly detecting a difference of $20 \%$ between the two treatments under the following assumptions: $\alpha=0.025$ one-sided and a coefficient of variation of the respective target variable(s) of $\leq 20 \%$.

The statistical comparisons between the two treatments were based on the mean differences of the target variables between baseline BAL and BAL obtained $24 \mathrm{~h}$ after endotoxin challenge. Statistical analysis was performed with an ANCOVA model. The dependent variable was change of the respective variable from baseline to $24 \mathrm{~h}$ after endotoxin challenge, while sex, age, baseline value, and treatment were used as independent co-variables. Based on the underlying hypothesis that roflumilast would reduce the influx of inflammatory cells compared to placebo, the level for the type I error rate of the test was set in accordance with a one-sided test-procedure at a level of $<2.5 \%$ (in accordance with the ICH E9 Statistical Principles for Clinical Trials, Note for Guidance on Statistical Principles for Clinical Trials CPMP/ICH/363/96, March 18, 1998).

Data are presented as mean \pm standard deviation (SD). Statistical analyses were carried out using $\mathrm{SAS}^{\circledR}$, release 8.02 (SAS Institute Inc., Cary, NC, USA). 


\section{RESULTS}

\section{Study Population}

Forty-eight subjects were enrolled into the study (Figure 2). Five subjects were not randomized at visit V1 because they were found ineligible according to predefined inclusion and exclusion criteria. Of the 43 subjects in the treatment phase, four subjects discontinued the study prematurely due to respiratory tract infection and one subject due to moderate headache. In addition, one subject discontinued the study due to elevated liver enzymes. This abnormality was already observed during baseline (at visit V0). The subject had been randomized by mistake and was excluded on the second day of treatment. The remaining 37 subjects underwent bronchoscopy with segmental endotoxin challenge on the last day of the treatment phase. After endotoxin challenge, in one subject of the roflumilast group BAL fluid was mistakenly obtained from a non-challenged segment. Therefore, the data was excluded from efficacy analysis. Subjects in both treatment groups were well matched with regard to demographic data and baseline characteristics (Table 1).

\section{Analysis of Anti-inflammatory Pharmacodynamic Effects}

Endotoxin but not saline induced a remarkable and significant influx of inflammatory cells into the airways. Neutrophils and eosinophils showed the most pronounced increases from baseline upon bronchial endotoxin challenge (about 885- and 440-fold, respectively, for placebo-treated subjects; Table 2). In contrast, lymphocytes and macrophages/monocytes were only modestly increased upon endotoxin challenge (Table 2). When the mean endotoxin-induced changes in the total number of inflammatory cells in BAL are considered, about 16- to 17 -fold increases relative to baseline were noted.

Compared with placebo, roflumilast treatment showed a statistically significant reduction of the endotoxin-induced change from baseline of total cells in BAL by about $36 \%$ $(\mathrm{p}=0.02$, Figure $3 \mathrm{a})$. Analysis of the individual cell types indicated that the observed 
roflumilast effects on total cell count were mainly driven by a significant attenuation of neutrophil (-39\%) and eosinophil (-74\%) influx (change from baseline) when compared with placebo $(\mathrm{p}=0.02$ and $\mathrm{p}=0.01$, respectively, Figure $3 \mathrm{~b}$ and $3 \mathrm{c}$, respectively). Further, a numerical trend towards attenuation of monocyte influx by roflumilast could be noted, however, the difference between both treatment groups was not statistically significant $(p=0.21$, Figure $3 \mathrm{~d})$. Also for lymphocytes, no significant treatment difference between the roflumilast and placebo could be noted upon endotoxin challenge $\left(5.44 \pm 2.96 \times 10^{3}\right.$ cells $/ \mathrm{ml}$ versus $7.27 \pm 2.78 \times 10^{3}$ cells $/ \mathrm{ml}$ in BAL fluid, respectively; $\mathrm{p}=0.34$ ).

Soluble inflammatory markers in BAL fluid at baseline and $24 \mathrm{~h}$ after saline or endotoxin challenge are presented in Table 3. Except for nitrate and nitrite, all inflammatory markers in BAL fluid were significantly increased after endotoxin challenge, but only slightly elevated after saline instillation in both treatment groups. There were no statistically significant differences between the treatments for any of the soluble inflammatory markers in BAL fluid.

\section{Safety Analysis}

Five subjects discontinued the study prematurely due to AEs: four subjects due to mild respiratory tract infections (three subjects in the roflumilast group and one subject in the placebo group) and one subject due to moderate headache (roflumilast group). All AEs resolved completely.

Adverse events were reported by $22(100.0 \%)$ subjects in the roflumilast group and $17(81.0 \%)$ subjects in the placebo group. A relevant proportion of the AEs were procedure-related and due to bronchoscopy with endotoxin challenge (e.g. throat irritation and decreased lung function test). Other frequent AEs in the roflumilast group were headache in 11 subjects $(50.0 \%)$, diarrhea in 8 subjects $(36.4 \%)$ and nausea in 7 subjects $(31.8 \%)$. In the placebo group, headache and nausea were reported in $2(9.5 \%)$ subjects each, while diarrhea 
was not observed. These adverse events, which were observed with a higher frequency in the roflumilast treatment group, are part of the known safety and tolerability profile of roflumilast. All AEs were mild with the exception of three moderate AEs (one episode of headache in a subject of the roflumilast group and two episodes of fever following bronchoscopy with BAL in one subject of the placebo group). No AE was of severe intensity and there was no serious AE. All AEs in this study resolved completely.

Physical examination, blood pressure, heart rate, and laboratory measurements did not reveal any treatment-emergent alterations by the study medication, except for a trend towards a slight decrease of mean body weight in the roflumilast group with a difference of $-1.4 \pm 1.7 \mathrm{~kg}$ versus baseline when compared with the placebo group $(-0.1 \pm 1.8 \mathrm{~kg})$. The subjects' lung function as measured at screening and at study termination was not altered.

\section{DISCUSSION}

Chronic airway inflammation is regarded as a key factor in the pathogenesis of COPD. Currently available treatments for COPD allow to prevent and control symptoms, reduce exacerbations, increase exercise tolerance, and improve health status [25]. However, many COPD patients do only benefit in terms of modest symptomatic improvements from currently available therapies. Therefore, new treatment approaches that target more effectively the specific inflammation characteristics in COPD are still warranted.

The identification and development of novel anti-inflammatory treatment concepts in COPD until proof-of-concept is lengthy, labor-intensive, and costly. This is mainly due to the apparent lack of well-established human pharmacodynamic models that would allow the identification of promising drug candidates in short-term studies with a reasonably low number of subjects. The model of induced pulmonary inflammation by segmental instillation of endotoxin in healthy subjects as first described by O'Grady et al. [7] could be a useful approach to effectively characterize the clinical potential of an apparent anti-inflammatory 
drug candidate already at an early development stage. However, to the best of our knowledge, segmental endotoxin challenge has not been used and validated as yet for the characterization of anti-inflammatory COPD treatment effects. Therefore, it was the purpose of our study to apply this model for the placebo-controlled assessment of treatment effects of roflumilast, a targeted PDE4 inhibitor. Further, we aimed at putting the results into perspective with previously observed roflumilast effects in pre-clinical COPD models as well as clinically obtained anti-inflammatory characteristics in COPD patients.

In our study, we found that roflumilast - compared with placebo - significantly reduced the endotoxin-induced influx of neutrophils, eosinophils, and total cells into the broncho-alveolar compartment. In contrast to the effect on granulocytes, endotoxin-induced recruitment of monocytes/macrophages and lymphocytes was only numerically lowered by roflumilast, but did not achieve statistical significance versus placebo. This predominance of roflumilast effects towards inhibition of granulocyte influx rather than lymphocyte and monocyte/macrophage increase has also been observed in animal models after cigarette smoke and endototoxin exposure $[15,26,27]$. Further, the roflumilast effect pattern in BAL observed in response to the segmental endotoxin challenge is also consistent with the previously demonstrated ability of roflumilast to reduce the number of neutrophils and eosinophils in induced sputum of patients with COPD and asthma, respectively, whereby the reduction of sputum neutrophilia in COPD patients was paralleled by improvements in lung function $[18,19]$. Taken together, the modulation of cellular inflammatory responses upon endotoxin challenge by roflumilast appears to be largely consistent with the previously shown pre-clinical and clinical anti-inflammatory characteristics of this targeted PDE4 inhibitor.

However, a randomized controlled clinical study in COPD patients with cilomilast, another investigational PDE4 inhibitor, showed that treatment for 12 weeks compared with placebo was associated with reductions in CD8+ T-lymphocytes and CD68+ macrophages in bronchial biopsies. In contrast to roflumilast, cilomilast did not alter the number or fraction of 
neutrophils in bronchial biopsies nor in induced sputum [28]. For a more detailed understanding whether this apparent discrepancy between predominant inhibition of neutrophilic versus monocytic inflammation may signify specific compound characteristics (roflumilast versus cilomilast) within the class of PDE4 inhibitors or rather reflecting differential PDE4 inhibitor effects in different compartments (bronchial mucosa versus BAL), the conduct of a roflumilast bronchial biopsy study in COPD patients would be required. We have not taken bronchial biopsies in our study because we enrolled healthy subjects in whom airway inflammation is virtually absent at baseline and bronchial biopsies after segmental instillation of endotoxin is hampered due to the fact that biopsy sampling from the subsegmental level (distal from endotoxin instillation) is very limited and often of poor quality.

In contrast to the observed significant and consistent treatment effects of roflumilast on cellular outcome variables in our study, cytokine/chemokine markers in BAL were apparently unaffected by roflumilast. However, the study by O'Grady and colleagues [7] indicated that the time courses of cellular and cytokine/chemokine inflammatory responses in BAL upon segmental endotoxin challenge are distinctly different, with maximum cytokine/chemokine increases occurring already at $6 \mathrm{~h}$ post challenge, while maximum cellular responses only occurring at $24 \mathrm{~h}$ post challenge. This observation implies that the investigation of drug effects on inflammatory cell and cytokine/chemokine responses by endotoxin challenge would require post-challenge bronchoscopies at different time points (i.e. at $6 \mathrm{~h}$ and $24 \mathrm{~h}$ ). From this methodological perspective, the present study using the 24-h bronchoscopy interval was therefore designed to primarily and adequately address the influence of roflumilast on cellular inflammatory markers but not on cytokine/chemokine responses, the latter were assessed only for exploratory purposes. This view is confirmed by our finding that post-challenge cytokines/chemokines at $24 \mathrm{~h}$ were numerically close to baseline levels. 
Two recent studies used a controlled clinical setting in humans with inhaled endotoxin to study the anti-inflammatory effect of salmeterol, prednisolone and the PDE4 inhibitor cilomilast $[8,9]$. Currently, there are no data published on the use of segmental endotoxin challenge for the characterization of anti-inflammatory effects of either established drugs or new drug candidates for the treatment of chronic inflammatory airway diseases such as COPD. Therefore, it is at present not possible to directly compare the pattern of the observed roflumilast effect in the endotoxin challenge model with already established COPD treatments (e.g. corticosteroids). However, our group conducted a study with a novel monoclonal MCP-1 antibody (ABN912) in patients with mild COPD. Here, we used the identical methodological approach of segmental instillation of endotoxin (i.e. at the identical dose of $4 \mathrm{ng} / \mathrm{kg}$ ) to investigate the anti-inflammatory characteristics of the compound in the airways. Interestingly, ABN912 significantly reduced BAL monocytes upon endotoxin challenge when compared to placebo, but did not alter the number of BAL neutrophils, macrophages, and lymphocytes [29]. This observation of distinctly different cellular effects of two antiinflammatory compounds with a different mode of action strongly suggests that the endotoxin challenge model indeed allows to distinguish between as well as to properly characterize differential anti-inflammatory drug effects.

In our study, roflumilast $500 \mu \mathrm{g}$ once daily was generally well tolerated. Safety results did not reveal any unexpected adverse treatment-emergent effect in terms of frequency or intensity of AEs. The observed trend towards a modest decrease of body weight may need further attention in future clinical studies with PDE4 inhibitors.

In conclusion, roflumilast significantly reduced the endotoxin-induced influx of total cells, neutrophils, and eosinophils into the airways of healthy subjects. This finding is consistent with anti-inflammatory properties of roflumilast shown in previous pre-clinical COPD models and clinical studies in COPD patients. The demonstrated anti-inflammatory potential of roflumilast may provide therapeutic benefits for the treatment of COPD, but 
needs to be further characterized at the level of cytokine/chemokine involvement and in additional compartments relevant to airway inflammation such as bronchial mucosal. Finally, we propose that the segmental endotoxin challenge model allows for a rapid, safe, and wellstandardized characterization and differentiation of anti-inflammatory drug effects in human airways.

\section{Conflict of Interest}

KS, DB, and RH are employees of ALTANA Pharma AG, Konstanz, Germany. The study described in this article has been designed, conducted, analyzed, and reported within the scope of their employment. JMH, MLM, FS, MM, and NK are employees of Fraunhofer ITEM, Hannover, Germany, which has received a research grant for this clinical trial from ALTANA Pharma AG and for other clinical trials in COPD from Novartis, GSK and Boehringer Ingelheim. JMH has been reimbursed by ALTANA Pharma AG for attending a conference and presenting the results of this study.

\section{Acknowledgements}

The authors thank Arnd Manegold, ALTANA Pharma AG, Konstanz, Germany for conceptual contribution and support in the conduct of the study and Angela Schilling, ALTANA Pharma AG, Konstanz, Germany for helpful suggestions during the preparation of this article. The authors thank Anthony F. Suffredini, National Institute of Health, Bethesda, MD, USA for his support to obtain National Institute of Health Clinical Center Reference Endotoxin. 


\section{References}

1. Pauwels RA, Rabe KF. Burden and clinical features of chronic obstructive pulmonary disease (COPD). Lancet 2004;364:613-620.

2. Pauwels RA, Buist AS, Calverley PM, Jenkins CR, Hurd SS. Global strategy for the diagnosis, management, and prevention of chronic obstructive pulmonary disease. NHLBI/WHO Global Initiative for Chronic Obstructive Lung Disease (GOLD) Workshop summary. Am J Respir Crit Care Med 2001;163:1256-1276.

3. Stanescu D, Sanna A, Veriter C, Kostianev S, Calcagni PG, Fabbri LM, Maestrelli P. Airways obstruction, chronic expectoration, and rapid decline of FEV1 in smokers are associated with increased levels of sputum neutrophils. Thorax $1996 ; 51: 267-271$.

4. Fujimoto K, Yasuo M, Urushibata K, Hanaoka M, Koizumi T, Kubo K. Airway inflammation during stable and acutely exacerbated chronic obstructive pulmonary disease. Eur Respir J 2005;25:640-646.

5. Hasday JD, Bascom R, Costa JJ, Fitzgerald T, Dubin W. Bacterial endotoxin is an active component of cigarette smoke. Chest 1999;115:829-835.

6. Thorn J. The inflammatory response in humans after inhalation of bacterial endotoxin: a review. Inflamm Res 2001;50:254-261.

7. O'Grady NP, Preas HL, Pugin J, Fiuza C, Tropea M, Reda D, Banks SM, Suffredini AF. Local inflammatory responses following bronchial endotoxin instillation in humans. Am J Respir Crit Care Med 2001;163:1591-1598.

8. Maris NA, de Vos AF, Dessing MC, Spek CA, Lutter R, Jansen HM, van der Zee JS, Bresser P, van der PT. Antiinflammatory effects of salmeterol after inhalation of 
lipopolysaccharide by healthy volunteers. Am J Respir Crit Care Med $2005 ; 172: 878-884$.

9. Michel O, Dentener M, Cataldo D, Cantinieaux B, Vertongen F, Delvaux C, Murdoch RD. Evaluation of oral corticosteroids and phosphodiesterase-4 inhibitor on the acute inflammation induced by inhaled lipopolysaccharide in human. Pulm Pharmacol Ther 2007;20:676-683.

10. Reid P. Roflumilast Altana Pharma. Curr Opin Investig Drugs 2002;3:1165-1170.

11. Lipworth BJ. Phosphodiesterase-4 inhibitors for asthma and chronic obstructive pulmonary disease. Lancet 2005;365:167-175.

12. Spina D. Phosphodiesterase-4 inhibitors in the treatment of inflammatory lung disease. Drugs 2003;63:2575-2594.

13. Bundschuh DS, Eltze M, Barsig J, Wollin L, Hatzelmann A, Beume R. In vivo efficacy in airway disease models of roflumilast, a novel orally active PDE4 inhibitor. $J$ Pharmacol Exp Ther 2001;297:280-290.

14. Hatzelmann A, Schudt C. Anti-inflammatory and immunomodulatory potential of the novel PDE4 inhibitor roflumilast in vitro. J Pharmacol Exp Ther 2001;297:267279.

15. Martorana PA, Beume R, Lucattelli M, Wollin L, Lungarella G. Roflumilast fully prevents emphysema in mice chronically exposed to cigarette smoke. Am J Respir Crit Care Med 2005;172:848-853. 
16. Wollin L, Bundschuh DS, Wohlsen A, Marx D, Beume R. Inhibition of airway hyperresponsiveness and pulmonary inflammation by roflumilast and other PDE4 inhibitors. Pulm Pharmacol Ther 2006;19:343-352.

17. Hargreave FE, Boulet LP, Cartier A, Efhimiadis A, Wenzel SE, Teichmann P, Hospers JJ, Knoerzer D, Bethke TD. The effect of roflumilast on sputum eosinophils in patients with asthma [abstract]. Ann Allergy Asthma Immunol 2005;96:203-204.

18. Grootendorst DC, Gauw SA, Sterk PJ, Bethke TD, Hospers JJ, Hiemstra PS, Rabe KF. Treatment with PDE4 inhibitor roflumilast reduces sputum neutrophil and eosinophil numbers in patients with COPD [abstract]. Proc Am Thorac Soc 2005;2:A543

19. Rabe KF, Bateman ED, O'Donnell D, Witte S, Bredenbroeker D, Bethke TD. Roflumilast--an oral anti-inflammatory treatment for chronic obstructive pulmonary disease: a randomised controlled trial. Lancet 2005;366:563-571.

20. Workshop summary and guidelines: investigative use of bronchoscopy, lavage, and bronchial biopsies in asthma and other airway diseases. $J$ Allergy Clin Immunol 1991;88:808-814.

21. Erpenbeck VJ, Hagenberg A, Dulkys Y, Elsner J, Balder R, Krentel H, Discher M, Braun A, Krug N, Hohlfeld JM. Natural porcine surfactant augments airway inflammation after allergen challenge in patients with asthma. Am J Respir Crit Care Med 2004;169:578-586.

22. Schaumann F, Borm PJ, Herbrich A, Knoch J, Pitz M, Schins RP, Luettig B, Hohlfeld JM, Heinrich J, Krug N. Metal-rich ambient particles (particulate matter 2.5) 
cause airway inflammation in healthy subjects. Am J Respir Crit Care Med 2004;170:898-903.

23. Erpenbeck VJ, Jorres RA, Discher M, Krentel H, Tsikas D, Luettig B, Krug N, Hohlfeld JM. Local nitric oxide levels reflect the degree of allergic airway inflammation after segmental allergen challenge in asthmatics. Nitric Oxide 2005;13:125-133.

24. Standardization of Spirometry, 1994 Update. American Thoracic Society. Am J Respir Crit Care Med 1995;152:1107-1136.

25. Barnes NC, Qiu YS, Pavord ID, Parker D, Davis PA, Zhu J, Johnson M, Thomson NC, Jeffery PK. Antiinflammatory effects of salmeterol/fluticasone propionate in chronic obstructive lung disease. Am J Respir Crit Care Med 2006;173:736-743.

26. Fitzgerald M, Spicer D, McAulay AE, Wollin L, Beume R. Effect of roflumilast on pulmonary inflammation in guinea pigs exposed to cigarette smoke [abstract]. Proc Am Thorac Soc 2006;3:A850

27. Wollin L, Barsig J, Marx D, Wohlsen A, Beume R. Inhibition by roflumilast versus cilomilast of pulmonary leukocyte accumulation and $\mathrm{TNF} \alpha$ release in a rat model of LPS-induced pulmonary neutrophilia [abstract]. Eur Respir $J$ $2003 ; 22: 107 \mathrm{~s}$

28. Gamble E, Grootendorst DC, Brightling CE, Troy S, Qiu Y, Zhu J, Parker D, Matin D, Majumdar S, Vignola AM, et al. Antiinflammatory effects of the phosphodiesterase-4 inhibitor cilomilast (Ariflo) in chronic obstructive pulmonary disease. Am J Respir Crit Care Med 2003;168:976-982.

29. Krug N, Larbig M, Bonner J, Mueller M, Erpenbeck VJ, Schaumann F, Lloyd P, Hohlfeld JM, Pascoe S. Anti-MCP-1-monoclonal antibody (ABN912) attenuates 
LPS-induced monocyte recruitment into the lung in patients with COPD [abstract]. Proc Am Thorac Soc 2006;3:A849 
TABLE 1. Demographic data and lung function characteristics of the study population.

\begin{tabular}{|c|c|c|}
\hline & $\begin{array}{c}\text { Placebo } \\
(n=19)\end{array}$ & $\begin{array}{c}\text { Roflumilast } 500 \mu \mathrm{g} \\
(\mathrm{n}=18)\end{array}$ \\
\hline Median age (range), years & $25(20-41)$ & $27(23-43)$ \\
\hline Height, $\mathrm{cm}^{*}$ & $176 \pm 9$ & $176 \pm 9$ \\
\hline Weight, kg ${ }^{*}$ & $73 \pm 14$ & $74 \pm 10$ \\
\hline BMI, $\mathrm{kg} / \mathrm{m}^{2}{ }^{*}$ & $23 \pm 2.8$ & $24 \pm 1.9$ \\
\hline \multicolumn{3}{|l|}{ Sex, n (\%) } \\
\hline male & $9(47)$ & $10(56)$ \\
\hline female & $10(53)$ & $8(44)$ \\
\hline \multicolumn{3}{|l|}{ Smoking habit, n (\%) } \\
\hline non-smokers & $17(89)$ & $17(94)$ \\
\hline ex-smokers & $2(11)$ & $1(6)$ \\
\hline $\mathrm{FEV}_{1}, \mathrm{~L}^{*}$ & $4.19 \pm 0.85$ & $4.21 \pm 0.78$ \\
\hline $\mathrm{FEV}_{1}, \%$ predicted ${ }^{*}$ & $105.7 \pm 10.8$ & $107.1 \pm 9.6$ \\
\hline $\mathrm{FVC}, \mathrm{L}^{*}$ & $5.06 \pm 1.12$ & $5.13 \pm 1.03$ \\
\hline
\end{tabular}


Roflumilast attenuates pulmonary inflammation

Hohlfeld et al.

TABLE 2. Cell counts in bronchoalveolar lavage fluid at baseline and following segmental bronchial challenge with saline or endotoxin in healthy subjects treated with placebo or roflumilast. Differential cell counts were analysed by light microscopy, while monocytes $^{\dagger}$ were additionally counted by flow cytometry. Values are given as mean \pm SD.

\begin{tabular}{|c|c|c|c|c|c|c|c|}
\hline & $\begin{array}{c}\text { Subjects } \\
\text { (n) } \\
\end{array}$ & $\begin{array}{l}\text { Total cells } \\
\left(\times 10^{3} / \mathrm{ml}\right)\end{array}$ & $\begin{array}{c}\text { Macrophages } \\
\text { / Monocytes } \\
\left(\mathbf{x} \mathbf{1 0}^{3} / \mathrm{ml}\right) \\
\end{array}$ & $\begin{array}{l}\text { Neutrophils } \\
(\text { (x 10 } / \mathrm{ml})\end{array}$ & $\begin{array}{l}\text { Eosinophils } \\
\left(\begin{array}{l}\text { x 10 } \\
\text { 10 } / \mathrm{ml})\end{array}\right.\end{array}$ & $\begin{array}{l}\text { Lymphocytes } \\
\left(\times 10^{3} / \mathrm{ml}\right)\end{array}$ & $\begin{array}{r}\text { Monocytes }^{\dagger} \\
\left(\begin{array}{l}\text { x 10 } \\
\text { 3 } / \mathrm{ml})\end{array}\right.\end{array}$ \\
\hline \multicolumn{8}{|l|}{ Placebo } \\
\hline Baseline & 19 & $100 \pm 50.0$ & $97.1 \pm 49.1$ & $1.42 \pm 2.00$ & $0.02 \pm 0.08$ & $5.33 \pm 6.20$ & $2.06 \pm 1.50$ \\
\hline Saline & 19 & $110 \pm 60.0$ & $96.4 \pm 49.6$ & $5.32 \pm 10.3$ & $0.20 \pm 0.33$ & $4.33 \pm 3.90$ & $2.65 \pm 2.38$ \\
\hline Endotoxin & 19 & $1720 \pm 960 \dagger$ & $447 \pm 153 \dagger$ & $1256 \pm 870 \dagger$ & $8.83 \pm 11.0 \dagger$ & $13.3 \pm 14.7 \dagger$ & $148 \pm 85.3 \dagger$ \\
\hline \multicolumn{8}{|c|}{ Roflumilast $500 \mu \mathrm{g}$} \\
\hline Baseline & 18 & $80.0 \pm 40.0$ & $79.5 \pm 36.6$ & $0.64 \pm 0.85$ & $0.07 \pm 0.14$ & $3.02 \pm 2.72$ & $1.33 \pm 1.14$ \\
\hline Saline & 18 & $140 \pm 160$ & $128 \pm 139$ & $7.02 \pm 18.8$ & $0.09 \pm 0.20$ & $4.67 \pm 5.17$ & $4.35 \pm 9.63$ \\
\hline Endotoxin & 17 & $1280 \pm 480 * \dagger$ & $435 \pm 239 \dagger$ & $836 \pm 314 * \dagger$ & $3.43 \pm 7.10^{*}$ & $7.71 \pm 11.2$ & $126 \pm 59.8 \dagger$ \\
\hline
\end{tabular}

from baseline to $24 \mathrm{~h}$ after endotoxin challenge. $\uparrow \mathrm{p}<0.01$ compared to baseline. 
Roflumilast attenuates pulmonary inflammation

Hohlfeld et al.

TABLE 3. Inflammatory markers in bronchoalveolar lavage fluid at baseline and following segmental bronchial challenge with saline or endotoxin in healthy subjects treated with placebo or roflumilast. Values are given as mean \pm SD.

\begin{tabular}{|c|c|c|c|c|c|c|c|c|}
\hline & $\begin{array}{c}\text { Subjects } \\
\text { (n) }\end{array}$ & $\begin{array}{l}\text { TNF- } \alpha \\
\text { (pg/ml) }\end{array}$ & $\begin{array}{c}\text { IL-6 } \\
\text { (pg/ml) }\end{array}$ & $\begin{array}{c}\text { IL-8 } \\
\text { (pg/ml) }\end{array}$ & $\begin{array}{r}\text { MMP-9 } \\
\text { (ng/ml) }\end{array}$ & $\begin{array}{l}\text { MCP-1 } \\
\text { (pg/ml) }\end{array}$ & $\begin{array}{c}\text { Nitrate } \\
(\mu \mathrm{mol} / \mathrm{l})\end{array}$ & $\begin{array}{c}\text { Nitrite } \\
(\mu \mathrm{mol} / \mathrm{l})\end{array}$ \\
\hline \multicolumn{9}{|l|}{ Placebo } \\
\hline Baseline & 19 & $16.2 \pm 2.9$ & $4.7 \pm 2.2$ & $30.5 \pm 2.8$ & $1.6 \pm 1.2$ & $35.8 \pm 13.5$ & $0.7 \pm 0.3$ & $0.1 \pm 0.1$ \\
\hline Saline & 19 & $16.2 \pm 2.6$ & $7.1 \pm 8.0$ & $31.5 \pm 2.7$ & $2.0 \pm 0.9$ & $36.6 \pm 16.3$ & $0.5 \pm 0.2$ & $0.2 \pm 0.2$ \\
\hline Endotoxin & 19 & $\begin{array}{l}55.2 \pm \\
22.2 \dagger\end{array}$ & $191 \pm 119 \dagger$ & $67.1 \pm 21.6 \dagger$ & $7.2 \pm 2.5 \dagger$ & $77.9 \pm 45.0 \dagger$ & $0.6 \pm 0.3$ & $0.2 \pm 0.2$ \\
\hline
\end{tabular}

Roflumilast $500 \mu \mathrm{g}$

$\begin{array}{lllllllll}\text { Baseline } & 18 & 16.1 \pm 1.6 & 3.7 \pm 1.9 & 31.2 \pm 0 & 1.0 \pm 0 & 33.4 \pm 9.50 & 0.6 \pm 0.3 & 0.3 \pm 0.5 \\ \text { Saline } & 18 & 16.0 \pm 1.6 & 7.0 \pm 6.8 & 31.4 \pm 3.9 & 1.5 \pm 0.9 & 407 \pm 23.3 & 0.6 \pm 0.3 & 0.1 \pm 0.1 \\ \text { Endotoxin } & 17 & 56.5 \pm & 219 \pm 147 \dagger & 79.7 \pm 34.2 \dagger & 7.3 \pm 2.7 \dagger & 81.0 \pm 37.0 \dagger & 0.7 \pm 0.3 & 0.1 \pm 0.1 \\ & & 20.8 \dagger & & & & & \end{array}$

Definition of abbreviations: TNF- $\alpha=$ tumor necrosis factor alpha; IL-6 = interleukin 6; IL-8 = interleukin 8;

MMP-9 = matrixmetalloproteinase 9; MCP-1 = monocyte chemoattractant protein $1, \mathrm{SD}=$ standard deviation.

$\dagger \mathrm{p}<0.01$ compared to baseline. No significant differences between groups were noted. 


\section{FIGURE LEGENDS}

Figure 1: $\quad$ Study design

Figure 2: $\quad$ Disposition of study subjects

Figure 3: Change of bronchoalveolar lavage cells after endotoxin challenge: change (mean and SEM) from baseline to $24 \mathrm{~h}$ after challenge with endotoxin compared to saline for total cells (A), monocytes as determined by flow cytometry (B), neutrophils (C), and eosinophils (D). * one-sided $\mathrm{p}<0.025$ for differences vs. placebo; $\mathrm{n} . \mathrm{s} .=$ not significant. 


\section{Figure 1}

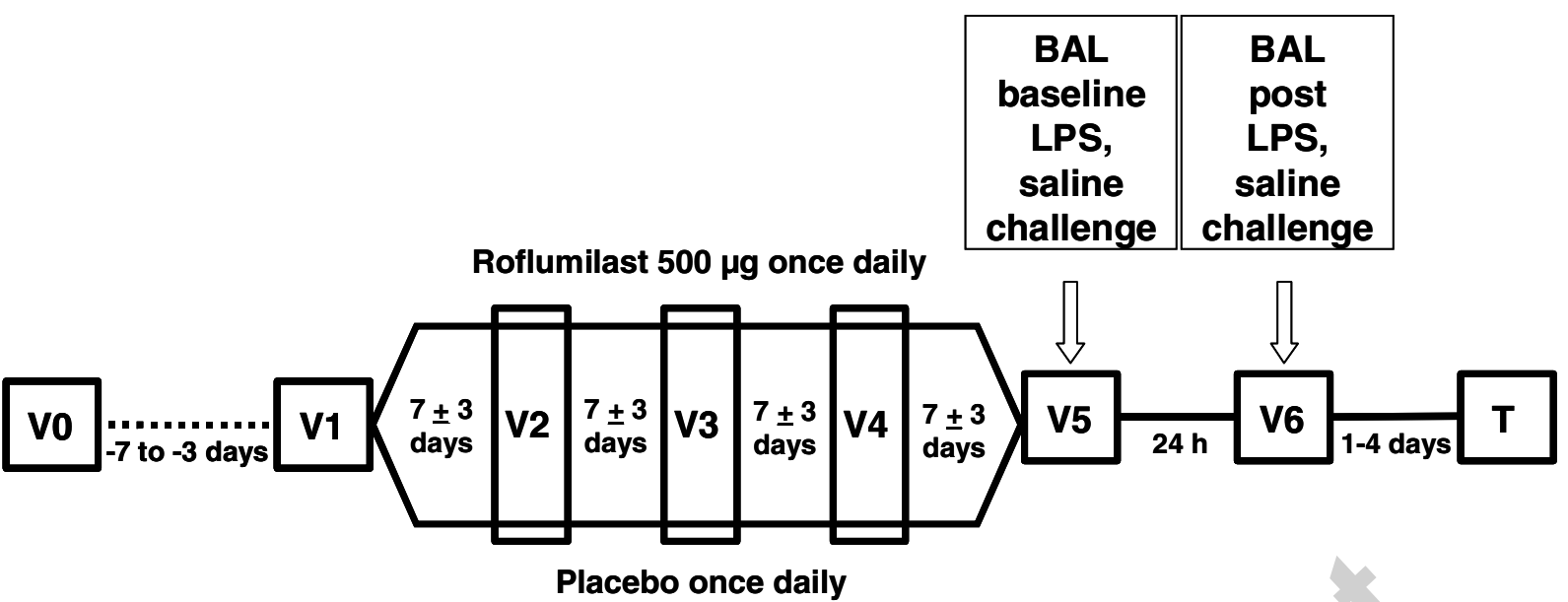

Inclusion period

$\sim 1$ week
Double-blind treatment period

$\sim 4$ weeks ( $28 \pm 3$ days)
Challenge and lavage
Termination visit 


\section{Figure 2}

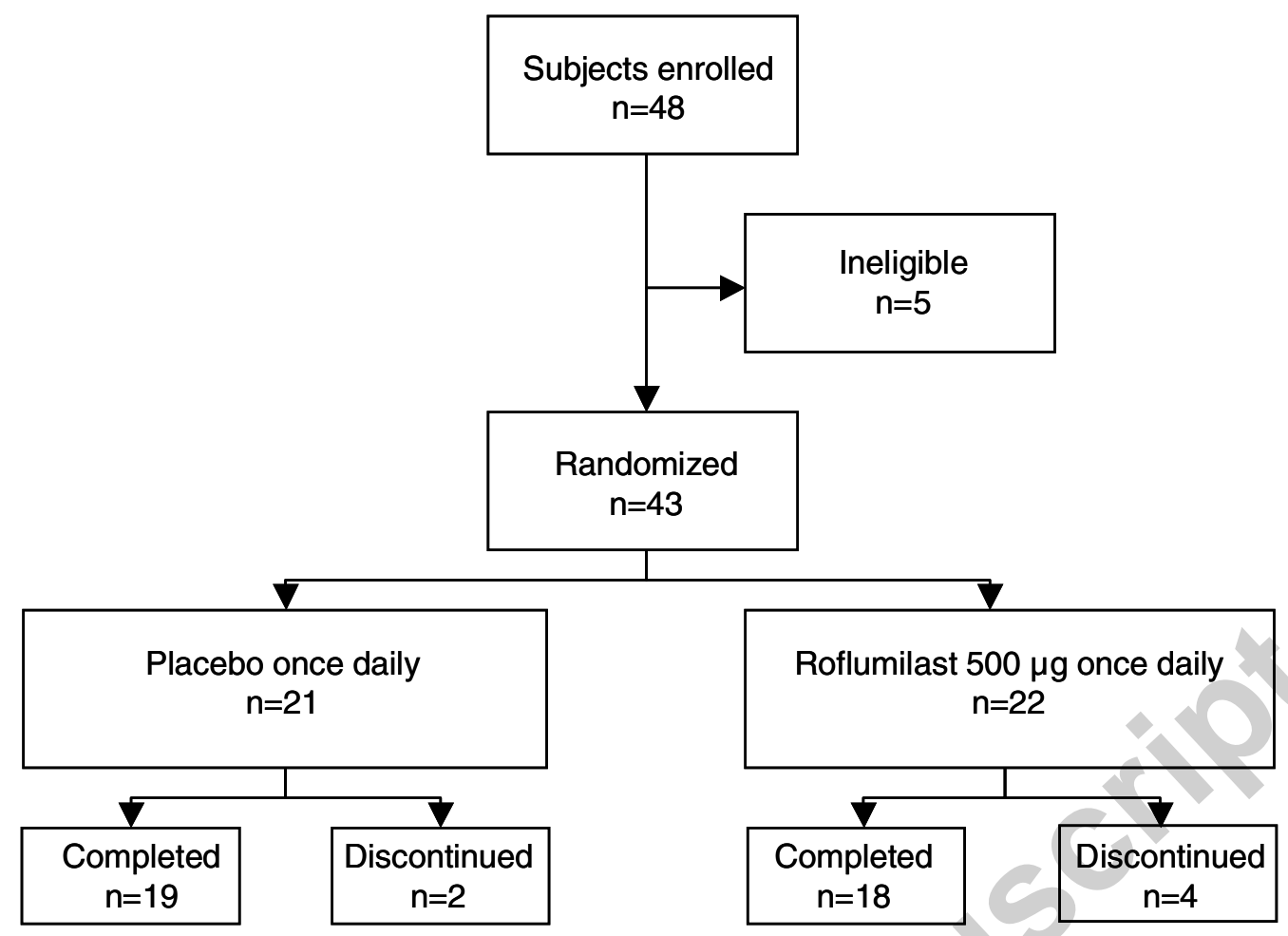


Figure 3 A

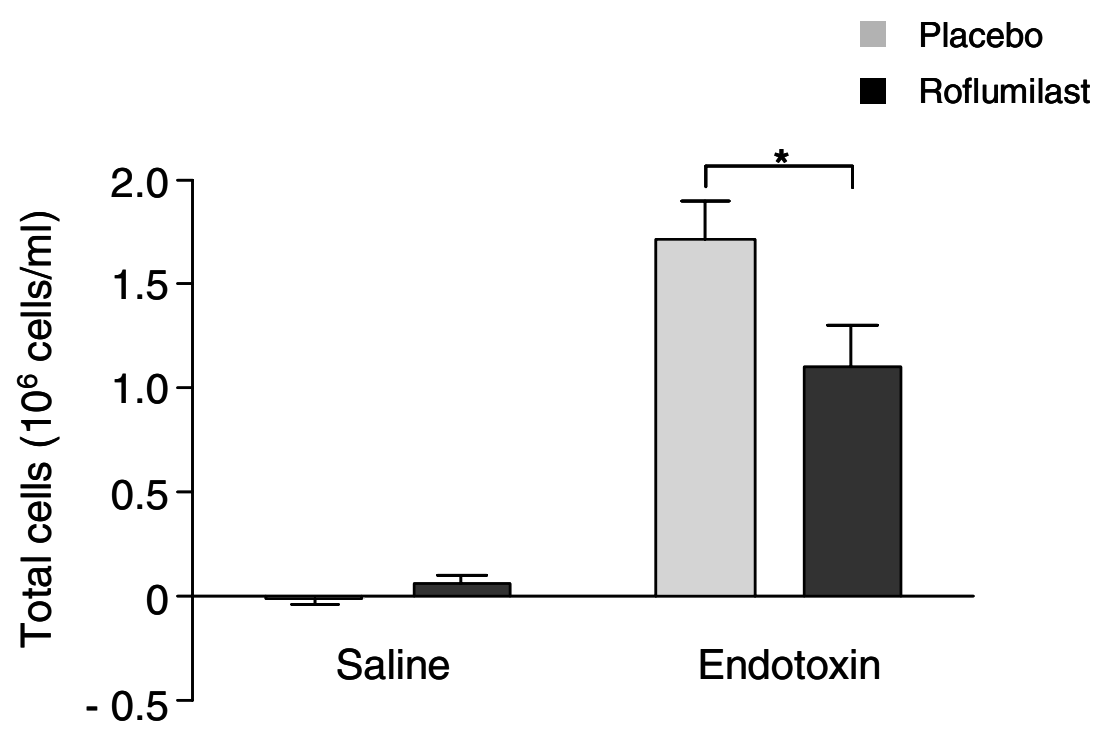

Figure 3 B

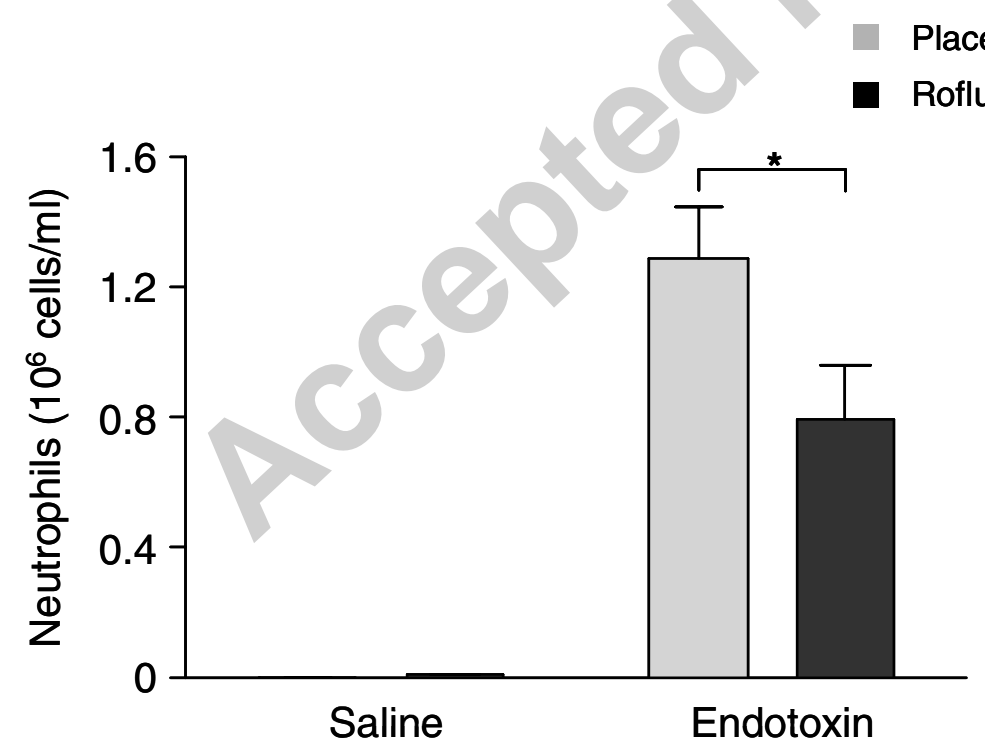


Figure 3 C

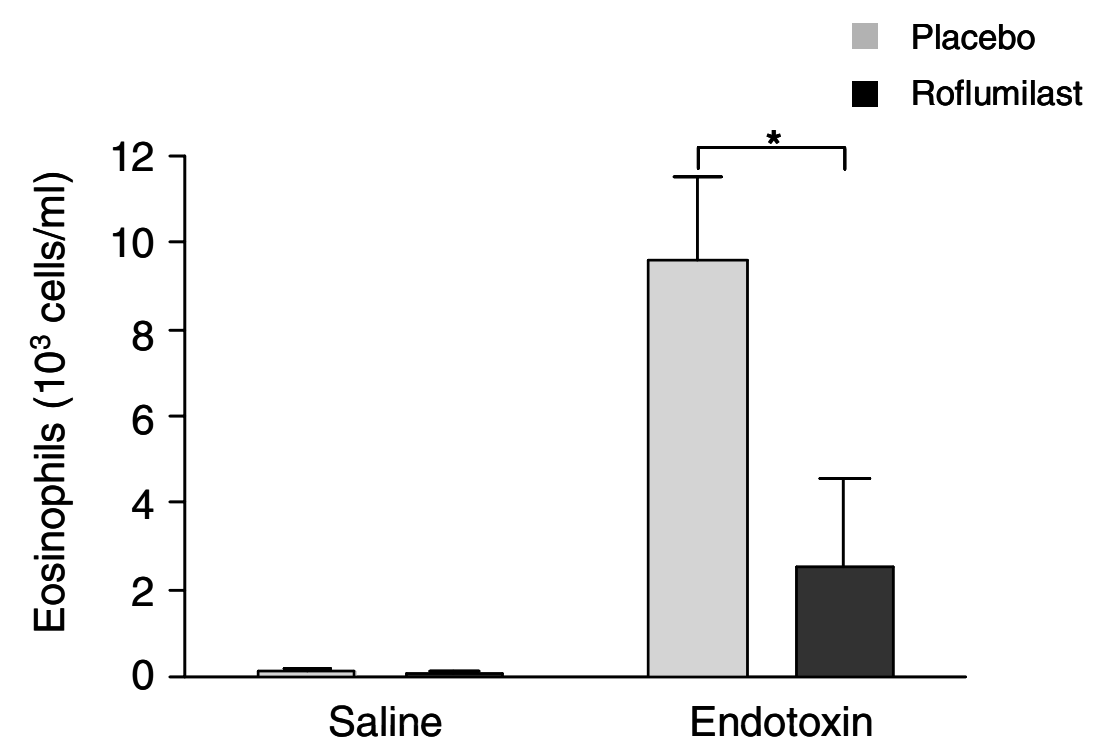

Figure 3 D

Placebo

Roflumilast

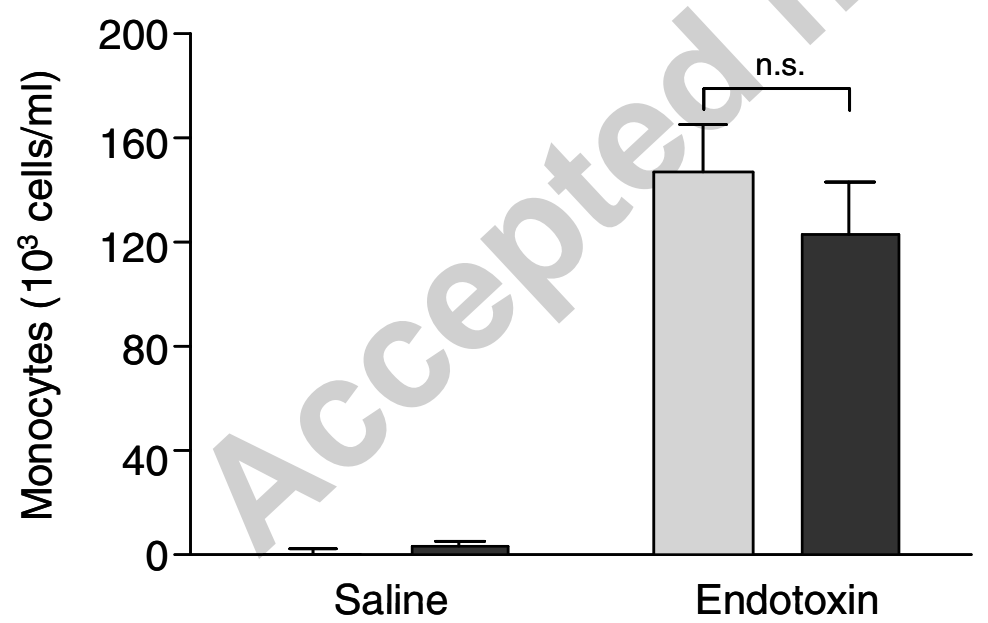

